\title{
Selenium Supplementation of Amaranth Sprouts Influences Betacyanin Content and Improves Anti-Inflammatory Properties via NF $k B$ in Murine RAW 264.7 Macrophages
}

\author{
Malgorzata Tyszka-Czochara ${ }^{1}$ - Pawel Pasko ${ }^{2,3} \cdot$ Pawel Zagrodzki $^{2,4}$. $^{2}$ \\ Ewelina Gajdzik $^{2}$ - Renata Wietecha-Posluszny ${ }^{5}$ - Shela Gorinstein ${ }^{6}$
}

Received: 26 March 2015 / Accepted: 26 June 2015 / Published online: 12 July 2015

(C) The Author(s) 2015. This article is published with open access at Springerlink.com

\begin{abstract}
Sprouts contain potent compounds which while influencing crucial transduction pathways in cell reveal antiinflammatory and anticancer activities. In this study, we report the biological activity for seeds and colourful sprouts of four types of edible amaranth, as amaranth has recently attracted interest due to its appreciable nutritional value. MTT assay conducted for the amaranth seeds and sprouts did not show any adverse effect on the viability of murine RAW 264.7 cells. As amaranth accumulates selenium, the sprouts were supplemented with this trace element $(10 \mathrm{mg} / \mathrm{L} ; 15 \mathrm{mg} / \mathrm{L} \mathrm{Se}$ as sodium selenite) while growing. Selenium concentration in sprouts was observed to be significantly correlated with betacyanins content of the tested species. The amounts of $\mathrm{Se}$ and betacyanins in sprouts varied for various Amaranth species. In the present study, Amaranthus cruentus sprouts with
\end{abstract}

Electronic supplementary material The online version of this article (doi:10.1007/s12011-015-0429-x) contains supplementary material, which is available to authorized users.

Pawel Pasko

paskopaw@poczta.fm

1 Department of Radioligands, Medical College, Jagiellonian University, Krakow, Poland

2 Department of Food Chemistry and Nutrition, Medical College, Jagiellonian University, Medyczna 9, 30-688 Krakow, Poland

3 Faculty of Health and Medical Science, Andrzej Frycz Modrzewski Krakow University, Krakow, Poland

4 Department of Nuclear Physical Chemistry, Institute of Nuclear Physics, Krakow, Poland

5 Department of Analytical Chemistry, Faculty of Chemistry, Jagiellonian University, Krakow, Poland

6 The Institute for Drug Research, School of Pharmacy, The Hebrew University, Hadassah Medical School, Jerusalem, Israel the highest betacyanins $(19.30 \pm 0.57-28.85 \pm 2.23 \mathrm{mg}$ of amaranthin/100 $\mathrm{g}$ of fresh weight) and high total selenium $(22.51 \pm 1.57-1044.75 \pm 73.08 \mu \mathrm{g} / \mathrm{L}$ in methanol extracts $)$ content prevented NFKB translocation to the cell nucleus and subsequently exerted an anti-inflammatory effect by significant decreasing inflammatory interleukin 6 production $(587.3 \pm 34.2-710.0 \pm 88.1 \mathrm{pg} / \mathrm{mL})$ in the cell culture of activated RAW 264.7 macrophages (vs LPS control $1520 \pm 114 \mathrm{pg} / \mathrm{mL})$.

Keywords Selenium-enriched amaranth sprouts .

Betacyanin · Murine macrophage cell line (RAW 264.7) ·

NF $k$ B translocation · Interleukin 6

\section{Introduction}

Daily nutrition may provide a variety of bioactive nutrients that may demonstrate physiological benefits and reduce the risk of chronic diseases. The new direction in human nutrition involves discovering and developing a new kind of food, so called functional food, whose functions exceed by far the basic nutritional ones. One of the prospective beneficial effects of the functional food on the organism is that it exerts a positive influence on inflammatory processes. It has been proven that vegetables, fruits and grains may present antiinflammatory activity and their effect is associated mostly with the content of phytochemicals such as phenolic acids, flavonoids or anthocyanins [1,2]. Since chronic inflammation is involved in aetiology of several malfunctions such as cardiovascular diseases, neurodegenerative disorders, diabetes mellitus and cancer, the investigation is highly required. Sprouts, the 'new kind' vegetables, which contain potent antioxidant compounds 
which act as free radical scavengers and, influencing crucial transduction pathways in cell, have been reported to reveal anti-inflammatory and anticancer activities [3-5].

Amaranth, a colourful pseudocereal, has recently attracted live interest due to its appreciable nutritional value. Several species of amaranth have edible seeds, sprouts and leaves. They are rich in unsaturated fatty acids, squalene and minerals, have higher protein content than most cereals do and are essentially gluten free. Thus, the plant family has become an important crop for agronomy and food industry. Especially, amaranth sprouts have recently received attention as a new product that might fortify human diet with beneficial components such as natural antioxidants, and it may impose beneficial effects on several aspects of human health [6]. Several studies reported appreciable bioactive properties of amaranth seeds [7, 8]; however, little is known about the biological activity of amaranth sprouts.

As the intensive colour of amaranth results from quite considerable betacyanins concentration in plant, it can provide an alternative phytochemicals source to beetroot. Betacyanins express red-violet colour, and so with regard to their chemical structure, they belong to betalains, i.e. water soluble pigments containing nitrogen. Natural products derived from Amaranthaceae family contain pigments such as amaranthin, isoamaranthin, iresinin, isoiresinin I, celosianin I, isocelosianin I, celosianin II and isocelosianin II $[9,10]$. In Amaranthus cruentus, only amaranthin and isoamaranthin were identified as representatives of amaranth-type betacyanins. Betanin and isobetanin as betanin-type betacyanins were found in Amaranthus powellii [9]. This group of natural pigments characteristic for Amaranthaceae family have been under close scrutiny due to their significant antioxidant activities. Amaranth betacyanins were also reported to act against oxidative stress-related disorders, though the mechanisms of their action in organism are not well documented [9-11]. Gallic acid, p-hydroxybenzoic acid, vanillic acid and rutin were found to be the most critical compounds for amaranth antioxidant properties in seeds and sprouts, out of all polyphenols though data on betacyanins are poor. The antioxidant activity of amaranth products, such as seeds, sprouts, cereals, flakes or bread, was confirmed with in vitro evaluation $[12,13]$ in vivo experiments, by using the rat model $[14,15]$.

On the other hand, the new trends in food production and consumption promote selenium rich plant products $[16,17]$. Amaranth sprouts were reported likely to accumulate selenium during their growth. Still, selenium is toxic to many plants valuable for human nutrition. The number of plants capable of accumulating selenium compounds applicable as a component of daily diet is very limited and includes Oonopsis $s p$., Xylorhiza sp., Neptunia sp., Astragalus sp., Morinda sp. and Stanleya $s p$. Nevertheless, one of these species meets dietary requirements, as for none safe consumption is guaranteed [18]. Hence, hope for amaranth sprouts to fill the gap arise. Among commonly used selenium compounds, selenite is found to be four times more toxic than selenomethionine, while for the latter one $\mathrm{LD}_{50}$ depends on the administration route and is equal to several $\mathrm{mg} /$ $\mathrm{kg}$ body mass. Higher doses of selenium compounds administered to animals cause cardio-respiratory effects to occur, hind limb paralysis, loss of body hair and even death [19]. Symptoms for selenium intoxication in humans include brittle hair and nails with apparent surface changes, pruritic rashes, garlic breath, nausea, dental caries, skin lesion and neurological impairment [19-21]. Epidemiologic data from China suggest that daily intake of $750-850 \mu \mathrm{g}$ sets the upper limit of safe dose [20].

Selenium revealed anti-inflammatory and anticancer activity in in vitro as well as in vivo studies [22]. It was indicated that selenium derivatives modulate various signal transduction pathways influencing cell signalling [22] and regulation of cell NFKB pathway [23]. The transcription factor NFKB plays a crucial role in the response of cell to the inflammatory signalling. In macrophages activated by an external or internal stimuli (IL-1, LPS, TNF- $\alpha$, ROS), the rapid activation of NFKB involves its translocation into nucleus, where it may regulate the transcription of pro-survival factors and immunity effectors such as IL-6 [24, 25]. The influence mechanism on immune system for food components includes the influence on cytokines and inflammatory mediators $\left(\mathrm{PGE}_{2}, \mathrm{NO}\right)$ [2]. $\mathrm{NFKB}$ as a master regulator of complex cell functions provides a very attractive therapeutic target for antiinflammatory pharmacological and nutritional interventions.

The study was primarily aimed at (1) determining the biological activity for seeds and sprouts of several amaranth species in relation to their betacyanins concentration and (2) checking their potency to modulate the immunological response. The sprouts were additionally supplemented with selenium. The biological activity for seeds and sprouts extracts of several amaranth species, namely Amaranthus cruentus, Amaranthus caudatus, Amaranthus paniculatus and Amaranthus tricolor are reported. The effect of amaranth seeds and sprouts on the viability of murine RAW 264.7 cells was measured with MTT assay. To assess the Se influence on amaranth sprouts properties, the sprouts were supplemented with $\mathrm{Se}$ at doses of 10 and $15 \mathrm{mg} / \mathrm{L}$. After harvesting, Se and betacyanins levels in plant material supplemented with Se while growing and without Se supplementation were measured. The potency of seeds and sprouts extracts of $A$. cruentus to modulate the immunological response after TNF $\alpha$ activation of RAW 264.7 macrophages was evaluated through NFKB translocation. The effect of incubation with $A$. cruentus extracts was 
confirmed by measuring the concentration changes of IL-6 released by RAW 264.7 cells stimulated with LPS.

\section{Material and Methods}

\section{Material}

Four species of edible amaranth seeds were used in sprouting. Voucher specimens were deposited in the Department of Food Chemistry and Nutrition, Faculty of Pharmacy, Medical College, Jagiellonian University with reference number AMCRU/PP/PL 1039 to A. cruentus (harvested in Poland), AMCAU/PP/PL 1040 to A. caudatus (harvested in Netherlands), AMPAN/PP/PL 1041 to $A$. paniculatus (harvested in Poland), AMTRI/PP/PL 1042 to A. tricolor (harvested in China). The four kinds of amaranth seeds were selected for sprouting as they are edible, widely available on the market and popular in cuisine over the world to replace flour, grains and vegetables [13, 26, 27]. Some of amaranth species, in particular, Amaranthus retroflexus and Amaranthus hybridus, may be harmful for living organism due to high levels of oxalates and nitrate/nitrite that may cause acute renal necrosis and perirenal oedema in ruminants, swine and horses [28].

\section{Sprouts Harvesting}

The amaranth seeds were immersed in tap water $\left(\mathrm{HCO}_{3}{ }^{-}\right.$ $131.06 \mathrm{mg} / \mathrm{L} ; \mathrm{F}^{-} 0.07 \mathrm{mg} / \mathrm{L} ; \mathrm{Mg}^{2+} 5.62 \mathrm{mg} / \mathrm{L} ; \mathrm{Ca}^{2+}$ $41.69 \mathrm{mg} / \mathrm{L} ; \mathrm{Na}^{+} 9.65 \mathrm{mg} / \mathrm{L}$ ) and tap water with two selenium concentration levels $(10 \mathrm{mg} / \mathrm{L} ; 15 \mathrm{mg} / \mathrm{L}$ Se as sodium selenite (Fluka)) for $3 \mathrm{~h}$ and then placed in clay vessels. As selenite does not affect agronomic species germination up to the concentration of about $30 \mathrm{mg} \mathrm{Se} / \mathrm{L}$ [29], we decide to establish the selenium doses at half and one third of such a threshold value. Sprouts were grown for 6 days after seeding at the controlled temperature of $24 \pm 2{ }^{\circ} \mathrm{C}$ and watered daily with tap water, and selenium supplemented water. All cultures were stored in natural light conditions. Selenium tolerance for various edible amaranth seeds was screened to evaluate the most appropriate amaranth genus for selenium enrichment [6]. The applied harvesting procedure for amaranth sprouts is described elsewhere [6].

\section{Extracts Preparation and Analysis of Betacyanin}

Seeds and sprouts samples of $0.2 \mathrm{~g}$ of fresh weight were homogenized in a cold mortar with $1.5 \mathrm{~mL}$ of cold distilled water. The procedures associated with betacyanin extraction were performed at $2-4{ }^{\circ} \mathrm{C}$ according to $\mathrm{Cao}$ et al. [30]. The obtained homogenates were transferred into tubes and centrifuged at $18.000 \mathrm{~g}$ at $4{ }^{\circ} \mathrm{C}$ for $15 \mathrm{~min}$. Then, $0.6 \mathrm{~mL}$ of supernatant was shaken with $1.0 \mathrm{~mL}$ of chloroform (Sigma-Aldrich) for $15 \mathrm{~min}$ and centrifuged at $4{ }^{\circ} \mathrm{C}$ for $30 \mathrm{~min}$. The aqueous phase absorbance was measured with spectrophotometer (Jasco V-530, Japan) at $536 \mathrm{~nm}$ [31]. Betacyanin content in amaranth seeds and sprouts was expressed as mg of amaranthin/100 g fresh weight. Each sample was evaluated in three replicates, and the results were expressed as mean value $\pm \mathrm{SD}$.

\section{Extracts Preparation for Evaluation of Selenium Concentration and for Cells Study}

Samples of four amaranth seeds, namely A. cruentus, A. caudatus, A. paniculatus, A. tricolor and fresh sprouts of the species $(4 \mathrm{~g})$, selenium free and supplemented with selenium at two doses of 10 and $15 \mathrm{mg} / \mathrm{L}$, were extracted with $35 \mathrm{~mL}$ of hot methanol (Dor-Chem) for $3 \mathrm{~h}$. The obtained extracts were decanted, centrifuged and stored in darkness in a freezer at $-20{ }^{\circ} \mathrm{C}$. For MTT analysis, and determination of NFKB nuclear translocation and IL-6 expression in RAW 264.7 , cells dry methanol extracts in concentration of $10 \mathrm{mg} /$ $\mathrm{mL}$ were obtained under reduced pressure and subsequently were dissolved in DMSO (Sigma-Aldrich).

\section{Selenium Concentration}

The 12-positional microwave system MARS X (CEM, Matthews, USA), equipped with temperature (RTP-300) and pressure (ESP-1500 Plus) sensors, was used for sample preparation. The system allowed programmable control of pressure and temperature. The sample portion of $0.3 \mathrm{~mL}$ (methanol extract) in $7 \mathrm{~mL}$ of concentrated $\mathrm{HNO}_{3}$ was digested at the maximum temperature of $200{ }^{\circ} \mathrm{C}$. The digestion conditions applied for the microwave system were $16 \mathrm{~min} / 960 \mathrm{~W}$ and $8 \mathrm{~min} / 1080 \mathrm{~W}$. Following digestion, the sample solution was cooled in the air to $25^{\circ} \mathrm{C}$ and purged under nitrogen flow for $10 \mathrm{~min}$. The Mini-vap device (Sigma Aldrich, Germany) was used to remove gaseous products with nitrogen. Finally, the sample was transferred into a $25 \mathrm{~mL}$ volumetric flask, mixed with $12.5 \mathrm{~mL}$ of $6 \mathrm{~mol} / \mathrm{L} \mathrm{HCl}$ and diluted to the mark with deionized water. For selenium concentration analysis, a double-channel atomic fluorescence spectrometer AFS-230 (Beijing Haiguang Instrument Co., China) with flow hydride-generation system was used. A cathode lamp (SeHCL) designed for AFS measurements, operating at pulsed current of $100 \mathrm{~mA}$, was used as the light source. The argonshielded gas flow and the carrier gas flow were 800 and $500 \mathrm{~mL} / \mathrm{min}$, respectively. The atomization process occurred in the $\mathrm{Ar}-\mathrm{H}_{2}$ flame at $200{ }^{\circ} \mathrm{C}$. The signals corresponding to selenium content in plant extracts were recorded and processed in the peak area mode with the use of an IBM 586 computer (Beijing Haiguang Instrument Co., China). 


\section{Cell Culture}

RAW 264.7 macrophage cell line (TIB 71, adherent cells from Mus musculus) from American Type Cell Culture collection, ATCC, USA, were cultured in Dulbecco's Modified Eagle's Medium (DMEM, ATCC, USA) supplemented with $10 \% v / v$ FBS, $100 \mathrm{IU} / \mathrm{mL}$ penicillin and $0.1 \mathrm{mg} / \mathrm{mL}$ streptomycin (Gibco Laboratories, NY, USA). The cells were kept at $37{ }^{\circ} \mathrm{C}$ in a humidified atmosphere of $5 \% \mathrm{CO}_{2}-95 \%$ air under standard conditions. The number of cells was assessed by automatic cell counter Countess (Gibco Laboratories, NY, USA). The cell culture morphology was investigated by means of inverted light microscope (Olympus CKX 41SF-5 microscope, Olympus, Germany).

\section{Cell Viability Assay}

The viability of RAW 264.7 cells incubated with variable concentrations of amaranth extracts was assayed with MTT test. Cells $\left(5 \times 10^{5}\right.$ cells/well $)$ were seeded onto the 96 multiwell plates (Sarstedt, Numbrecht, Germany) and kept for $24 \mathrm{~h}$ as adherent cultures at $37^{\circ} \mathrm{C}$. Then, different dry methanol amaranth extracts dissolved in DMSO were added to the appropriate cell wells, and incubation was performed for $24 \mathrm{~h}$. Six concentrations of amaranth extracts: $1 \mathrm{mg} / \mathrm{mL} ; 500 \mu \mathrm{g} / \mathrm{mL}$; $100 \mu \mathrm{g} / \mathrm{mL} ; 10 \mu \mathrm{g} / \mathrm{mL} ; 1 \mu \mathrm{g} / \mathrm{mL} ; 0.1 \mu \mathrm{g} / \mathrm{mL}$ of medium were tested. The cells cultured in medium were used as positive control (100\% of growth), whereas the cells incubated with addition of $20 \mathrm{mM} / \mathrm{L}$ hydrogen peroxide to medium provided the negative control ( $0 \%$ of growth). The test was conducted as described previously [32]. The absorbance was measured at $550 \mathrm{~nm}$ (the reference wavelength of $690 \mathrm{~nm}$ ) using Universal Microplate Reader ELX800NB (Bio-Tek Instruments INC, Winooski, VT, USA). The following formula was applied to report the results: (average OD value over three measurements for each experimental group/average OD value of control group) $\times 100 \%$. Each experiment was repeated in triplets.

\section{Translocation of Transcription Factor NFKB}

RAW 264.7 cells were seeded onto plates at the density of $2 \times 10^{6}$ cells/well and kept overnight. Then, the cells were incubated for $24 \mathrm{~h}$ with $10 \mu \mathrm{g} / \mathrm{mL}$ of $A$. cruentus extracts as follows: (a) seeds, (b) Se free sprouts, (c) Se supplemented sprouts (10 $\mathrm{mg} \mathrm{Se} / \mathrm{L}$ added to water) and (d) Se supplemented sprouts (15 $\mathrm{mg} \mathrm{Se} / \mathrm{L}$ added to water). The cells with addition of vehicle to the media served as the controls. The same experiment was performed for all the experimental groups exposed overnight to extracts as described above, but following $24 \mathrm{~h}$ incubation $10 \mathrm{ng} / \mathrm{mL}$ of TNF $\alpha$ was added to each of the experimental group in order to stimulate $\mathrm{NF} \kappa \mathrm{B}$ translocation from cytoplasm to the nucleus. Then, the incubation was continued for the next $24 \mathrm{~h}$.
The cells of all the experimental groups were lysed for immunoblot analysis in buffers (Thermo Fisher Scientific Inc., USA) with a protease inhibitor cocktail (Merck, Darmstadt, Germany). Nuclear and cytoplasm fractions were separated from cells with organelles extraction kit (Merck, Darmstadt, Germany). The protein samples were resolved via standard SDS-PAGE and then transferred to PVDF membranes. The membranes were blocked with buffer contained $1 \%$ casein in TBST $(20 \mathrm{mM} / \mathrm{L}$ of Tris-hydrochloride, $\mathrm{pH} 7.5$, $150 \mathrm{mM} / \mathrm{L} \mathrm{NaCl}, 0.05 \%$ Tween 20). Immunoblotting was performed using a 1:500 dilution of an anti-NFkB antibody (Cell Signalling, Danvers, MA, USA), a 1:250 dilution of an anti-phospho NFKB (Cell Signalling Technology, USA), followed by a 1:6000 dilution of an HRP-linked anti-mouse secondary antibody (Santa Cruz Biotech., Santa Cruz, CA, USA). GAPDH (1:1000, Cell Signalling, Danvers, MA, USA) and histone H4 (1:250, Cell Signalling, Danvers, MA, USA) were the loading controls for cytoplasmic and nuclear fractions, respectively. The specific immunoreactivity was demonstrated by enhanced chemiluminescence. The immunoblots were developed using the Super Signal West Pico Chemiluminescent Substrate Kit (Pierce Chemical, Rockford, IL, USA) using Gel Logic Imaging System 1500 (Kodak; Molecular imaging System Corestea Health Inc., Rochester, NY, USA). Total protein was measured by the Bradford method using bovine serum albumin as a standard. Each experiment was repeated three times.

\section{Interleukin 6 (IL6) Release}

RAW 264.7 cells were seeded onto 96 multi-well plates $\left(5 \times 10^{5}\right.$ cells/well $)$ and exposed to an amaranth extracts for $24 \mathrm{~h}$ as described above. The cells with addition of vehicle to the media served as the controls. Following incubation with extracts, $10 \mathrm{ng} / \mathrm{mL}$ of LPS was added to every culture well to increase NFKB activity and IL-6 release from the activated macrophages and the incubation was continued for the next $24 \mathrm{~h}$. IL-6 release (pg/mL) was determined in the culture medium with an ELISA quantitative test (Gen-Probe Inc., USA). The assay was performed according to the manufacturer protocol with a universal microplate reader ELX800 MB. The absorbance was measured at $450 \mathrm{~nm}$; the reference was $630 \mathrm{~nm}$. Each experiment was repeated three times.

\section{Statistical Analysis}

The experimental data are shown as means $\pm \mathrm{SD}$. Analysis was performed with one-way ANOVA followed by the Duncan post hoc test and the significant difference was set at ${ }^{*} p<0.05,{ }^{* *} p<0.01$.

The multivariate principal component analysis (PCA) method was applied to address the issue of interactions between the investigated parameters. It was assumed that the 
parameters with absolute values of their weights, i.e. coordinates, higher than 0.3 with respect to the first or second principal component were considered to be correlated [33]. To gain quantitative evidence weight of the results, for pairs of the considered parameters algebraic products of their corresponding weights and the corresponding angle cosine, i.e. the angle determined by two lines on the PCA plot connecting the origin of the coordinative system with the coordinates of both parameters, were calculated. The cosine multiplication is a correction factor for relative position of these parameters in a multivariate space - for orthogonal states, no correlation occurs, whatever big values their weights take. The results of such 'corrective' calculations are called correlation weights $(\mathrm{CW})$.

Cluster analysis (CA) was chosen to group objects, i.e. our samples, into similar categories. This analysis was performed after data standardization. Ward agglomeration procedure and the Euclidean distance were assumed for the grouping method and the distance function, respectively. The number of distinctive clusters was calculated with the Mojena's rate applied as criterion.

Statistical calculations were carried out using the commercially available packages SPSS Statistics 22 (IBM, USA) and Statistica PL v.10 (StatSoft, USA) and the software delivered by MP System Co. (Poland).

\section{Results and Discussion}

\section{Betacyanins Concentration in Amaranth Seeds and Sprouts}

Amaranthaceae family has recently attracted interest due to its appreciable nutritional value and considerable concentration of phytochemicals combined with a high biological activity of various amaranth products. The precise biological action of several compounds abundant in amaranth, such as betacyanins, is poorly understood. In the present study, the concentrations of betacyanins in seeds and sprouts of edible amaranth species, namely $A$. cruentus, A. caudatus, A. paniculatus and $A$. tricolor were measured. The total concentrations of betacyanins recalculated for the amount of amaranthin per $100 \mathrm{~g}$ of $\mathrm{FW}$ are shown in Table 1. The seeds contained significantly $(p<0.01)$ lower amount of betacyanins when compared to sprouts. The betacyanins concentrations in the amaranth seeds ranged from $1.09 \pm 0.06 \mathrm{mg}$ to $6.00 \pm 0.28 \mathrm{mg}$ (expressed as $\mathrm{mg}$ amaranthin $/ 100 \mathrm{~g} \mathrm{FW}$ ). The highest amount of the pigments was presented in seeds of A. caudatus, compared to the remaining groups. The differences between the others seed samples were not statistically significant. In the control sprouts, grown without Se supplementation, the highest amount of betacyanins was present in A. cruentus material $(28.85 \pm 2.23 \mathrm{mg} / 100 \mathrm{~g} \mathrm{FW})$, whereas the lowest one in A. tricolor $(9.23 \pm 0.13 \mathrm{mg} / 100 \mathrm{~g} \mathrm{FW}$, the difference was statistically significant at $p<0.05$ ). All the tested sprouts samples of $A$. caudatus and $A$. paniculatus contained similar amount of betacyanins (about $14 \mathrm{mg} / 100 \mathrm{~g}$ FW).

As reported by Cai et al. [9], the analysis of betacyanins content is usually conducted in fresh plant material including amaranth sprouts [31], while the analysis of food with addition of Amaranthus pigment, for jelly and ice cream that contained dried A. cruentus, genotype $\mathrm{Cr} 072$, was also reported [31]. It was demonstrated that total betacyanins in the various wild amaranth species may range from 46 to $199 \mathrm{mg} / 100 \mathrm{~g} \mathrm{FW}$, while cultivated amaranth species contained significantly more betacyanins than the wild ones [9]. The influence of physical variables such as light, as well as chemical factors such as methyl jasmonate, ethylene or salicylic acid, on betacyanins content in Amaranthus mangostanus seedlings was also studied by Cao et al. [30]. In particular, betacyanins synthesis was concluded to be enhanced by light and methyl jasmonate treatment.

\section{Accumulation of Se in Amaranth Seeds and Sprouts}

Under this study, amaranth sprouts were demonstrated to be a likely source of betacyanins and Se, when supplemented with selenium ions while growing. Amaranth sprouts capability to accumulate Se, reported before [6], was found to be very encouraging with regards to using amaranth sprouts as functional food. The amaranth sprouts for A. tricolor watered with addition of $15 \mathrm{mg} / \mathrm{L}$ of $\mathrm{Se}$ (data not shown here) were measured to accumulate $82 \pm 1.8 \mathrm{mg} \mathrm{Se} / \mathrm{kg}$ dry weight [6]. Under present experimental conditions, the sprouts of $A$. caudatus and $A$. cruentus were found to accumulate much higher

Table 1 The content of betacyanins in amaranth seeds and sprouts, expressed as mg of amaranthin per $100 \mathrm{~g}$ of fresh weight (FW) ( $n=3)$

\begin{tabular}{llccc}
\hline Sample & Seeds & Sprouts (Aq) & Sprouts (10 mg Se/L) & Sprouts (15 mg Se/L) \\
\hline A. cruentus & $1.09 \pm 0.06$ & $28.85 \pm 2.23$ & $21.92 \pm 0.92^{*}$ & $19.30 \pm 0.57^{*}$ \\
A. caudatus & $6.00 \pm 0.28$ & $14.75 \pm 0.74$ & $14.30 \pm 0.16$ & $13.53 \pm 0.27$ \\
A.paniculatus & $1.15 \pm 0.19$ & $14.76 \pm 0.75$ & $14.31 \pm 0.20$ & $13.50 \pm 0.30$ \\
A. tricolor & $1.41 \pm 0.05$ & $9.23 \pm 0.13$ & $6.95 \pm 0.05^{*}$ & $7.20 \pm 0.21^{*}$ \\
\hline
\end{tabular}

${ }^{*} p<0.05$ (significant difference compared with control (sprouts watered only with water)) 
amounts of this trace element, namely $1044.8 \pm 73.1 \mu \mathrm{g} \mathrm{Se} / \mathrm{L}$ and $1200.9 \pm 150.1 \mu \mathrm{g} \mathrm{Se} / \mathrm{L}$ of methanol extracts, respectively. The amounts of Se in samples of all the tested amaranth species watered with water $(0 \mathrm{mg} \mathrm{Se} / \mathrm{L})$ were significantly lower than in samples with addition of selenium (see Table 2). Two sprouts species (A. paniculatus, A. tricolor) supplemented with $15 \mathrm{mg} \mathrm{Se} / \mathrm{L}$ indicated a higher accumulation efficiency than the ones supplemented with $10 \mathrm{mg} \mathrm{Se} / \mathrm{L}$, as the observed increase of selenium concentrations in their stems was much higher than resulting solelt from its increased concentration in the growing media. The lowest concentrations of Se were observed in seeds of the tested species. Lintschinger et al. [34] evaluated selenium influence on germination for eight edible seeds of alfalfa, barley, millet, oat, pea, rye, sunflower and wheat. Unfortunately, barley, millet, oat, pea and rye sprouts showed a major reduction in the germination rates with selenium doses present. Sprouts of wheat and alfalfa occurred to be less resistant, and selenium content was enriched up to the concentrations of 100 and $150 \mathrm{mg}$ of Se/kg of dry mass, with the best results obtained for sunflower sprouts where selenium concentrations up to $900 \mathrm{mg}$ of Se/ $\mathrm{kg}$ of dry mass were recorded. Mung bean sprouts (Vigna radiate) whose practical application (it contained $223.45 \mathrm{mg} \mathrm{Se} / \mathrm{kg}$ ) was evaluated by Chinrasri et al. [35], provide another good selenium source. Also, Sugihara et al. [36] cultivated 28 sprouts species from 10 families in a high selenium environment. The highest selenium concentration of over $30 \mu \mathrm{g} / \mathrm{g}$ wet weight was obtained for Chinese cabbage, turnip, nozawana (a type of turnip), broccoli, kintoki (a Japanese carrot) and parsley.

\section{The Effect of Se Supplementation on Betacyanins Concentration in Amaranth Seeds and Sprouts}

Since Se plays an essential role in plants development, it was much of an interest to check whether this trace element may influence betacyanins concentration in amaranth species. The Se influence on betacyanin level in A. cruentus and A. tricolor seeds and sprouts was clearly proven in our study (Table 1). Selenium caused significant reduction in betacyanin level for both species, while for the other two, no changes were observed.
Whether the mechanism of such interaction is intrinsic to specific sprout species remains to be investigated.

Se impact on betacyanin production in plants is to the best of our knowledge reported for the first time. As the role of Se in synthesising such phytochemicals and in metabolism is poorly understood, more detailed studies to explain their mechanisms are required.

\section{Effect of Amaranth Seeds and Sprouts on RAW 264.7 Macrophages Viability/Proliferation}

It requires strong evidence of safety to recommend amaranth sprouts as a new nutritional product for humans. Therefore, in the present study, cytotoxicity of seeds and sprouts extracts was assessed. MTT cell viability/proliferation assay is one of the essential tests performed while evaluating the effects of sprouts on mammalian cells. Kim et al. [3] estimated antiproliferative action of mung bean sprouts on human pulmonary carcinoma cell line (Calu-6) and human gastric carcinoma cell line (SNU-601). Rutabaga sprouts examinations revealed cytotoxic activity in human hepatoma HepG2 cells culture [4]. Yoshida et al. [37] reported antiproliferative activity of Seenriched radish sprouts against tumour cells in vitro. In the present study, RAW 264.7 murine macrophages have been used to the effect of $A$. cruentus $A$. caudatus, A. paniculatus and $A$. tricolor on cells viability. RAW 264.7 cells were consistently used in experiments on the influence of plant chemicals on cells viability and immune reactions, and specifically, this cell line retains essential immune properties characteristic for macrophages in vivo.

The results obtained with MTT assay confirmed that only $24 \mathrm{~h}$ incubation of cells with the highest concentration of extracts $(1 \mathrm{mg} / \mathrm{mL})$ reduced proliferation of cells. The addition of $1 \mathrm{mg} / \mathrm{mL}$ of each extract significantly decreased cells viability for all the tested amaranth seeds and all the sprouts; only $10 \%$ of the cells were alive and biochemically active in all the cultures, see Online Resource, while extracts of the concentration of $10 \mu \mathrm{g} / \mathrm{mL}$ or less did not tend to decrease cells viability. Tendency for the tested amaranth seeds and sprouts to influence cells viability was similar.

A. paniculatus and A. tricolor sprouts grown in water without Se were less toxic to RAW 264.7 cells than the

Table 2 The total selenium concentration $(\mu \mathrm{g} / \mathrm{L})$ in methanol extracts $(n=3)$ of edible amaranth seeds and sprouts samples (Amaranthus cruentus; Amaranthus caudatus; Amaranthus paniculatus; Amaranthus tricolor) after 6 days of growing in water based solutions $(0,10$ and $15 \mathrm{mg}$ Se/L)

\begin{tabular}{lrrrr}
\hline Sample & \multicolumn{1}{l}{ Seeds } & Sprouts (Aq) & Sprouts (10 mg Se/L) & Sprouts (15 mg Se/L) \\
\hline A. cruentus & $14.21 \pm 0.99$ & $22.51 \pm 1.57$ & $842.58 \pm 58.98$ & $1044.75 \pm 73.08$ \\
A. caudatus & $5.00 \pm 0.35$ & $15.67 \pm 1.10$ & $840.16 \pm 75.20$ & $1200.92 \pm 150.13$ \\
A.paniculatus & $8.55 \pm 1.70$ & $36.5 \pm 2.39$ & $329.58 \pm 23.10$ & $920.75 \pm 69.85$ \\
A. tricolor & $4.50 \pm 0.75$ & $29.42 \pm 2.24$ & $723.83 \pm 19.89$ & $1256.33 \pm 168.90$ \\
\hline
\end{tabular}


corresponding seeds. The Se supplemented growth of sprouts caused cells viability to decrease effectively for the dose of $500 \mu \mathrm{g} / \mathrm{mL}$ of extracts than for the same dose of extracts for sprouts grown without Se. The effect was particularly apparent for A. cruentus and A. paniculatus. On the other hand, the addition of $1 \mathrm{mg} / \mathrm{mL}$ A. paniculatus seeds extract reduced the amount of living cells to less than $10 \%$, while about $20 \%$ of the cells survived in Se supplemented sprouts cultures at the same dose (see Online Resource $C$ ). The effect of minor cytotoxicity of $A$. paniculatus coincides with the lowest amount of Se accumulated in these sprouts (Table 2). The reason for such irregularities is not clear to us at the moment.

Kim and Milner [38] demonstrated that Se can retard cell proliferation and promote apoptosis in vitro. This observation is in accordance with the effect of $A$. caudatus sprouts watered with $\mathrm{Se}$ (Online Resource B), which accumulated the highest amount of Se, and at concentration of $500 \mu \mathrm{g} / \mathrm{uL}$ caused the highest decrease in cell proliferation $(10 \mathrm{mg} / \mathrm{mL}$ of supplemented Se, see Online Resource B).

The data indicate that at concentration below $10 \mu \mathrm{g} / \mathrm{mL}$ amaranth sprouts with/without Se had no toxic effect on RAW 264.7 cells. A similar effect was also observed in the study on the influence of rutabaga sprouts on CHO-K1 cells [4].

\section{The Correlation Structure of Parameters}

The statistically significant PCA model with two significant components was derived. The eigenvalue for the first component was 1.41 , and 1.12 was for the second. The first two components accounted for 32.8 and $29.0 \%$ of the variance in the original parameters. The plot for the first two principal components is shown in Fig. 1. Se concentration was shown to be positively correlated with betacyanin concentration $(\mathrm{CW}=0.296)$, and the latter parameter was also correlated

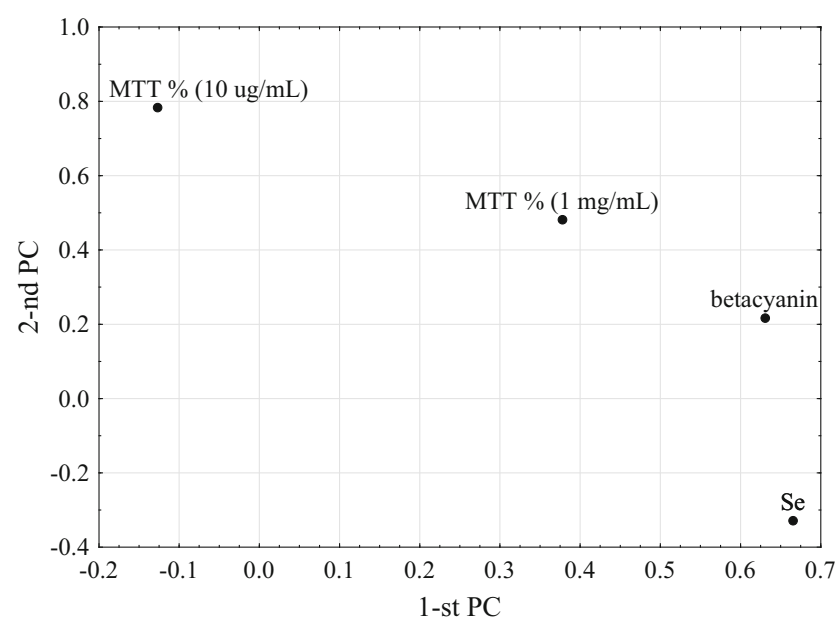

Fig. 1 Plot of the first two principal components with MTT\% $(1 \mathrm{mg} / \mathrm{mL})(\mathrm{CW}=0.200)$. For two parameters, resulting from MTT assay, namely MTT $\%(10 \mu \mathrm{g} / \mathrm{mL})$ and MTT\% $(1 \mathrm{mg} / \mathrm{mL})$, a high positive correlation $(\mathrm{CW}=0.330)$ was also found. The revealed positive correlation between Se and betacyanin levels can be contributed to the fact that all the samples (i.e. both seeds and sprouts) were taken into account in PCA analysis; seeds with selenium amount several times lower also contained much fewer betacyanins as compared with the sprouts, regardless of sprout Se supplementation.

\section{The Cluster Analysis of Samples}

It was possible to distinguish three different clusters of samples (A, B, C) (Fig. 2) by means of the cluster analysis. Obviously, members of each cluster display some common distinctive characteristics. Cluster B was the most homogenous one and consisted of only two samples of $A$. paniculatus sprouts treated with either 10 or $15 \mathrm{mg} \mathrm{Se} / \mathrm{L}$. Cluster C contained all the other sprouts treated with selenium and, additionally, A. cruentus seeds. A specific regularity was found for this cluster as the three sub-clusters were formed by the sprouts of the same species that differed only in selenium concentration in the growing media. On the contrary, cluster A contained all the other samples that were not treated with selenium. Hence, with the only exception for A. cruentus seeds, the cluster structure of studied samples followed our expectations and clearly reflected different sprouts characteristics in the original multivariate space of parameters. Therefore, it is worth noting that the Wards' minimum-variance method of clustering was successfully applied. This method tends to join clusters with a small number of samples and is biased towards finding clusters with roughly the same number of samples. The three resulting clusters remain reasonably

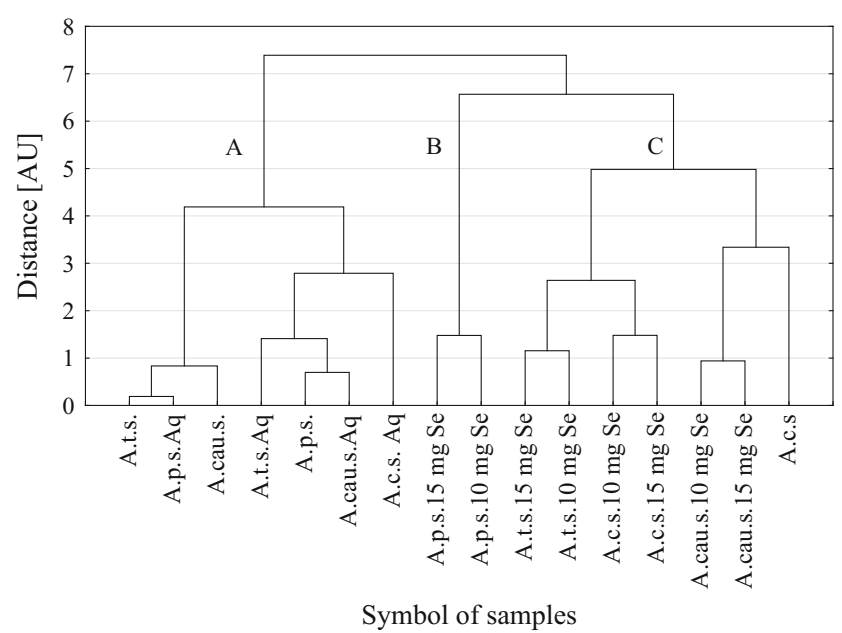

Fig. 2 Dendrogram of similarity of samples. Mojena's rate: $d=5.44$. Meaning of abbreviations: A. c.-A. cruentus; A.cau.-A. caudatus; A. p.-A. paniculatus; A. t.-A. tricolor; s.-seeds; s. Aq-sprouts watered with water without Se; $s .10 \mathrm{mg} \mathrm{Se}$-sprouts watered with $10 \mathrm{mg} \mathrm{Se} / \mathrm{L}$ water; $s .15 \mathrm{mg} \mathrm{Se}$ — sprouts watered with $10 \mathrm{mg} \mathrm{Se} / \mathrm{L}$ water 
established and, apparently, there is no random association when considering their composition.

\section{Effect of Amaranth Seeds and Sprouts on Translocation of Transcription Factor NFKB into the Cell Nucleus in RAW 264.7 Macrophages Stimulated with TNF $\alpha$}

The present study was also aimed at evaluating amaranth seeds, normal sprouts and Se supplemented sprouts capabilities to modulate immune response in cells and exert an antiinflammatory activity. In the subsequent experiments, only A. cruentus seeds and sprouts were tested. A. cruentus samples combined the highest amount of betacyanins with the appreciable ability for Se accumulation and minor antiproliferative effect in the cultured cells when compared with the other amaranth species. Additionally, A. cruentus is of high nutritional value and significant importance for gluten free food production $[12,13]$.

Several studies reported dietary betacyanin to modulate the biochemical processes and regulate pathways essential for cell survival though the exact mechanisms remains unclear. The overall effects of betacyanins were associated with their ability to scavenge free radicals [9]. We considered that these bioactive particles may exert the effect not only via diminishing the oxidative stress but also through a direct effect on the signal transduction pathways. ROS induced by TNF- $\alpha$ are capable to activate nuclear factor NFKB, which results in the enhanced production of pro-inflammatory cytokines such as IL-6. The activation of NFKB by TNF- $\alpha$ and LPS involves a classic pathway, which causes the transportation of p $65 / \mathrm{p} 50$ proteins to the nucleus and the subsequent changes in particular gene transcription [39, 40]. Therefore, the cellular localization of $\mathrm{p} 65 / \mathrm{p} 50$ subunits is considered essential for regulating cell response via NFKB.

To investigate whether $A$. cruentus seeds and sprouts affect the nuclear translocation of $\mathrm{NF} \kappa \mathrm{B}$, Western blot analysis of p65 subunit of NFKB was carried out in unstimulated (Fig. 3, left panel) and stimulated (Fig. 3, right panel) RAW 264.7 macrophages. As shown in the right panel of Fig. 3, the control RAW 264.7 macrophages treated with TNF- $\alpha$ caused dephosphorylation of protein and further translocation of $\mathrm{p} 65$ subunit of NFKB from cytoplasm to the cell nucleus. The amount of nuclear NFKB was markedly decreased upon preexposure to seeds and sprouts extracts, and the effect was more pronounced for sprouts (Fig. 3, the right panel). Since Se anti-inflammatory effect was reported [22], under this study, we combined the experiments on the antioxidant effects of amaranth sprouts supplemented with Se to find out whether such modification may result in enhancing anti-inflammatory action of amaranth. The results demonstrated that $24 \mathrm{~h}$ pretreatment of RAW 264.7 macrophages with $A$. cruentus sprouts grown with or without of Se prevented the translocation of the transcription factor NFKB in cell to the same extent. Notably, Se supplementation of sprouts caused expression of cytosolic p65 subunit of NFKB in unstimulated RAW 264.7 macrophages to increase (the left panel of Fig. 3). The amount of p65 NFKB protein in cells was higher, but no influence on the process of $\mathrm{NF} \kappa \mathrm{B}$ translocation was observed.

The obtained data on inhibiting NFKB translocation by A. cruentus seeds and sprouts extracts suggest that amaranth has anti-inflammatory effect in stimulated mammalian macrophages. The anti-inflammatory potency of amaranth protein extract was also reported elsewhere [7].

\section{The Effect of Amaranth Seeds and Sprouts on IL-6 Release in RAW 264.7 Macrophages Stimulated with LPS}

As discussed previously, it was well established that betacyanin acts against oxidative stress. In vivo ROS, cytokines and several immune mediators are involved in the stimulation of inflammatory response in macrophages. During the inflammation process, the internal (TNF $\alpha)$ and external (LPS) stimuli also trigger macrophages to release IL6 through NFKB activation, which in turn contributes to the inflammatory reaction [41].

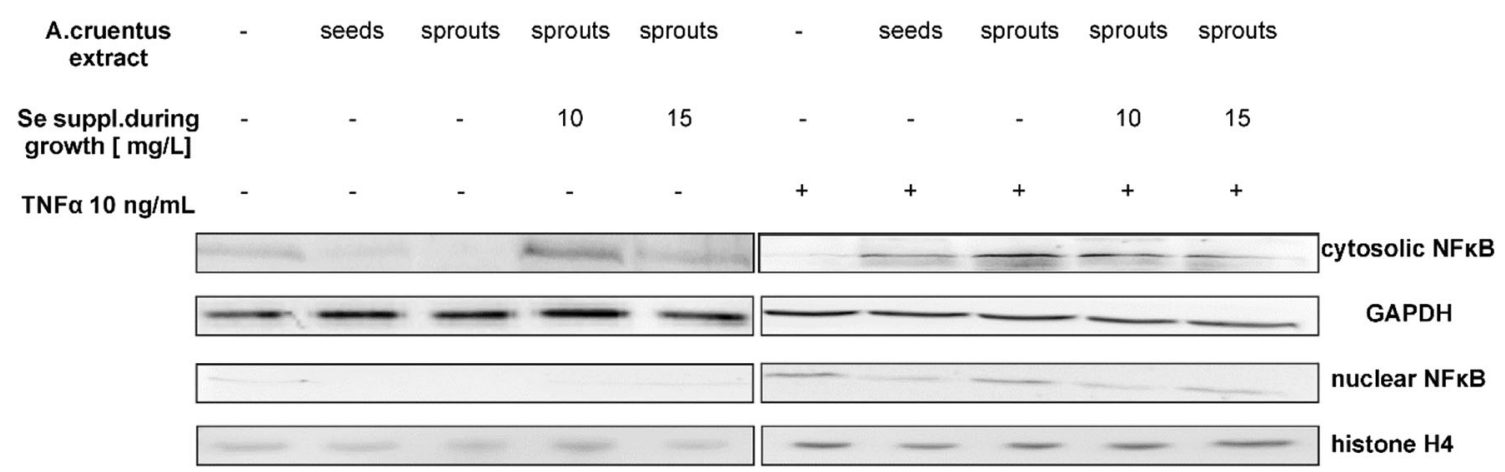

Fig. 3 Effect of A. cruentus seeds and sprouts extracts in RAW 264.7 macrophages after $24 \mathrm{~h}$ of extracts pre-treatment $(10 \mu \mathrm{g} / \mathrm{mL})$. In the right panel, TNF- $\alpha$ induced translocation of $\mathrm{NFKB}$, in the left panel,

unstimulated cells. Western blot was performed to detect cytosolic (normalized to GAPDH) and nuclear (normalized to histone H4) levels of p65 subunit. Experiment was repeated three times with similar results 
Table 3 Effect of A. cruentus seeds and sprouts extracts on LPS $(10 \mathrm{ng} / \mathrm{mL})$ induced IL-6 release $[\mathrm{pg} / \mathrm{mL}]$ from RAW 264.7 macrophages after $24 \mathrm{~h}$ of extracts pre-treatment $(10 \mu \mathrm{g} / \mathrm{mL})$

\begin{tabular}{|c|c|c|c|c|c|c|}
\hline Sample & Positive control (LPS) & Negative control & Seeds & Sprouts (Aq) & Sprouts (10 mg Se/L) & Sprouts (15 mg Se/L) \\
\hline IL-6[pg/mL] & $1520 \pm 114$ & $25.3 \pm 4.65$ & $846.0 \pm 73.45$ & $710.0 \pm 88.1$ & $674.0 \pm 51.9$ & $587.3 \pm 34.2$ \\
\hline
\end{tabular}

Values are mean and SD of three experiments. The differences between IL- 6 concentrations in the $A$. cruentus treated medium and in the positive control medium were significant at $p<0.05$

In our experiments, the activation of RAW 264.7 cells with $10 \mathrm{ng} / \mathrm{mL}$ LPS caused the synthesis of a pro-inflammatory cytokine, IL-6 (Table 3) to enhance. It was demonstrated that $24 \mathrm{~h}$ pre-treatment of RAW 264.7 macrophages with extracts prepared from $A$. cruentus seeds and sprouts (grown with and without of Se) led to a significant decrease in IL-6 concentration in culture medium, in contrast to the positive control cultures (incubated with LPS) where a substantial IL-6 release from cells was observed. IL- 6 concentrations in all the cell cultures incubated with $A$. cruentus were significantly lower at $p<0.05$ than in the medium of stimulated control cells. RAW 264.7 cells incubated with extracts of sprouts supplemented with $15 \mathrm{mg} / \mathrm{L}$ of Se while growing secreted a significantly smaller amount of IL-6 into the culture medium than for cells incubated with seeds extracts. As Western blot analysis of NF KB translocation did not resolved whether Se supplemented to growing sprouts might cause any differences in the transcription factor activation to occur, the existing difference between the action of $A$. cruentus seeds and $15 \mathrm{mg} / \mathrm{L} \mathrm{Se}$ supplemented sprouts extracts on IL-6 release may be contributed to an unknown mechanism triggered by Se in the stimulated macrophages. Considering the mechanism of Se action in the cell where this trace element is the essential component of antioxidant enzymes, e.g. thioredoxin reductase (TR) and glutathione peroxidase (GPX), it may inhibit inflammation both by reducing ROS level and by decreasing cell lipid peroxidation [38]. Kretz-Remy et al. [42] suggested that increase of cellular GPX (cGPX) activity can interfere with NFKB activation with concomitant minor influence on gene expression or protein stability.

\section{Concluding Remarks}

In the present paper, we have demonstrated that $A$. cruentus seeds and sprouts extracts treatment had anti-inflammatory effect on RAW 264.7 macrophages by preventing the TNF- $\alpha$ induced translocation of NFKB to the nucleus, which effect was followed by a decreased release of IL-6 from LPS activated cells. The biological effects of seeds and sprouts extracts were correlated with betacyanins concentrations in plants and sprouts ability to accumulate Se. None of the tested amaranth species decreases mammalian cells proliferation and viability. Though further studies are required to recognize the precise mechanisms, it can be concluded that Se supplemented amaranth sprouts may be considered as a novelty for potent functional food, which can contribute to the lower risk of chronic inflammation related diseases due to beneficial influence on NFKB signalling pathway. Amaranth seeds and sprouts may become a valuable source of betacyanin as an alternative to beetroot, and in addition to its unique biological and nutritive properties, attractively red-violet coloured amaranth sprouts may help to promote proper nutritional habits in consumers.

Acknowledgments This project was supported in part by the grants from Polish Ministry of Science and Higher Education, project K/DSC/ 000805, K/ZDS/001294, K/ZDS/005624 and by the European Union within the European Social Fund, The Human Capital Operational Programme, Priority 4 Higher Education and Science, Objective Strengthening and development of learning quality at the level of higher education and increasing the number of graduates of the fields in key areas for knowledge-based economy, Sub-objective Improving the quality of educational offer of higher education institutions entitled Internationalisation of Andrzej Frycz Modrzewski Krakow University (Project No. 1/POKL/ 4.1.1/2010).

Conflict of Interest The authors declare that they have no conflict of interest

Open Access This article is distributed under the terms of the Creative Commons Attribution 4.0 International License (http:// creativecommons.org/licenses/by/4.0/), which permits unrestricted use, distribution, and reproduction in any medium, provided you give appropriate credit to the original author(s) and the source, provide a link to the Creative Commons license, and indicate if changes were made.

\section{References}

1. Hole AS, Grimmer S, Jensen MR, Sahlstrøm S (2012) Synergistic and suppressive effects of dietary phenolic acids and other phytochemicals from cereal extracts on nuclear factor kappa B activity. Food Chem 133(3):969-977

2. Tan AC, Konczak I, Ramzan I, Zabaras D, Sze DMY (2011) Potential antioxidant, antiinflammatory, and proapoptotic anticancer activities of Kakadu plum and Illawarra plum polyphenolic fractions. Nutr Cancer 63(7):1074-1084

3. Kim DK, Jeong SC, Gorinstein S, Chon SU (2012) Total polyphenols, antioxidant and antiproliferative activities of different extracts in mungbean seeds and sprouts. Plant Foods Hum Nutr 67(1):71-75 
4. Pasko P, Bukowska-Strakova K, Gdula-Argasinska J, TyszkaCzochara M (2013) Rutabaga (Brassica napus L. var. napobrassica) Seeds, Roots, and Sprouts: A Novel Kind of Food with Antioxidant Properties and Proapoptotic Potential in Hep G2 Hepatoma Cell Line. J Med Food 16(8):749-759

5. Pasko P, Sulkowska-Ziaja K, Muszynska B, Zagrodzki P (2014) Serotonin, melatonin, and certain indole derivatives profiles in rutabaga and kohlrabi seeds, sprouts, bulbs, and roots. LWT-Food Sci Technol 59(2):740-745

6. Pasko P, Gdula - Argasinska J, Podporska-Carroll J, Quilty B, Wietecha - Posluszny R, Tyszka - Czochara M, Zagrodzki P (2014). Influence of selenium supplementation on fatty acids profile and biological activity of four edible amaranth sprouts as new kind of functional food. J Food Sci Technol (in press) 10.1007/ s13197-014-1602-5

7. Montoya-Rodríguez A, Mejía EG, Dia VP, Reyes-Moreno C, Milán-Carrillo J (2014) Extrusion improved the anti-inflammatory effect of amaranth (Amaranthus hypochondriacus) hydrolysates in LPS-induced human THP-1 macrophage-like and mouse RAW 264.7 macrophages by preventing activation of NF-KB signaling. Mol Nutr Food Res 58(5):1028-1041

8. Perales-Sánchez JX, Reyes-Moreno C, Gómez-Favela MA, MilánCarrillo J, Cuevas-Rodríguez EO, Valdez-Ortiz A, GutiérrezDorado R (2014) Increasing the antioxidant activity, total phenolic and flavonoid contents by optimizing the germination conditions of amaranth seeds. Plant Foods Hum Nutr 69:196-202

9. Cai YZ, Sun M, Corke H (2005) Characterization and application of betalain pigments from plants of the Amaranthaceae. Trends Food Sci Tech 16(9):370-376

10. Strack D, Vogt T, Schliemann W (2003) Recent advances in betalain research. Phytochemistry 62(3):247-269

11. Delgado-Vargas F, Jiménez AR, Paredes-López O (2000) Natural pigments: carotenoids, anthocyanins, and betalains - characteristics, biosynthesis, processing, and stability. Cr Rev Food Sci 40(3):0173-0289

12. Alvarez-Jubete L, Wijngaard H, Arendt EK, Gallagher E (2010) Polyphenol composition and in vitro antioxidant activity of amaranth, quinoa buckwheat and wheat as affected by sprouting and baking. Food Chem 119(2):770-778

13. Chlopicka J, Pasko P, Gorinstein S, Jedryas A, Zagrodzki P (2012) Total phenolic and total flavonoid content, antioxidant activity and sensory evaluation of pseudocereal breads. LWT-Food Sci Technol 46(2):548-555

14. Paśko P, Bartoń H, Zagrodzki P, Chłopicka J, Iżewska A, Gawlik M, Gawlik M, Gorinstein S (2011) Effect of amaranth seeds in diet on oxidative status in plasma and selected tissues of high fructosefed rats. Food Chem 126(1):85-90

15. Paśko P, Bartoń H, Zagrodzki P, Gorinstein S (2011) Effect of amaranth seeds (Amaranthus cruentus) in the diet on some biochemical parameters and essential trace elements in blood of high fructose-fed rats. Nat Prod Res 25(8):844-849

16. Reilly C (1998) Selenium: a new entrant into the functional food arena. Trends Food Sci Tech 9(3):114-118

17. White PJ, Broadley MR (2009) Biofortification of crops with seven mineral elements often lacking in human diets-iron, zinc, copper, calcium, magnesium, selenium and iodine. New Phytol 182(1):49-84

18. Terry N, Zayed AM, de Souza MP, Tarun AS (2000) Selenium in higher plants. Annu Rev Plant Phys 51(1):401-432

19. Reid ME, Stratton MS, Lillico AJ, Fakih M, Natarajan R, Clark LC, Marshall JR (2004) A report of high-dose selenium supplementation: response and toxicities. J Trace Elem Med Biol 18(1):69-74

20. Yang GQ, Wang SZ, Zhou RH, Sun SZ (1983) Endemic selenium intoxication of humans in China. Am J Clin Nutr 37(5):872-881
21. Sheehan TMT (1998) The toxicology of selenium. Bull Intern Assoc Forensic Tox 28(3):16-20

22. Brozmanová J, Mániková D, Vlčková V, Chovanec M (2010) Selenium: a double-edged sword for defense and offence in cancer. Arch Toxicol 84(12):919-938

23. Shalini S, Bansal MP (2007) Alterations in selenium status influences reproductive potential of male mice by modulation of transcription factor NFKB. Biometals 20(1):49-59

24. Karin M, Delhase M (2000) The IkB kinase (IKK) and NF-kB: key elements of proinflammatory signalling. In Seminars in immunology. Academic Press 12(1):85-98

25. Libermann TA, Baltimore D (1990) Activation of interleukin-6 gene expression through the NF-kappa B transcription factor. Mol Cell Biol 10(5):2327-2334

26. Nascimento A C, Mota C, Coelho I, Gueifão S, Santos M, Matos AS, Gimenez A, Lobo M., Samman N., Castanheira I (2014) Characterisation of nutrient profile of quinoa (Chenopodium quinoa), amaranth (Amaranthus caudatus), and purple corn (Zea mays L.) consumed in the North of Argentina: Proximates, minerals and trace elements. Food Chem 148: 420-426.

27. Shukla S, Bhargava A, Chatterjee A, Srivastava J, Singh N, Singh SP (2006) Mineral profile and variability in vegetable amaranth (Amaranthus tricolor). Plant Foods Hum Nutr 61(1):21-26

28. Kessell AE, Boulton J, Krebs GL, Quinn JC (2015) Acute renal failure associated with Amaranthus species ingestion by lambs. Aust Vet J 93(6):208-213

29. Carlson CL, Kaplan DI, Adriano DC (1989) Effects of selenium on germination and radicle elongation of selected agronomic species. Environ Exp Bot 29:493-498

30. Cao S, Liu T, Jiang Y, He S, Harrison DK, Joyce DC (2012) The effects of host defence elicitors on betacyanin accumulation in Amaranthus mangostanus seedlings. Food Chem 134(4):1715-1718

31. Cai Y, Corke H (1999) Amaranthus betacyanin pigments applied in model food systems. J Food Sci 64(5):869-873

32. Tyszka-Czochara M, Paśko P, Reczyński W, Szlósarczyk M, Bystrowska B, Opoka W (2014) Zinc and propolis reduces cytotoxicity and proliferation in skin fibroblast cell culture: total polyphenol content and antioxidant capacity of propolis. Biol Trace Elem Res 160(1):123-131

33. Furdal S (1989) Statistical modelling in empirical research. The Institute of Sport, Warsaw[in Polish]

34. Lintschinger J, Fuchs N, Moser J, Kuehnelt D, Goessler W (2000) Selenium-enriched sprouts. A raw material for fortified cerealbased diets. J Agric Food Chem 48:5362-5368

35. Chinrasri O, Chantiratikul P, Thosakham W, Atiwetin P, Chumpawadee S, Saenthaweesuk S, Chantiratikul A (2009) Effect of selenium-enriched bean sprout and other selenium sources on productivity and selenium concentration in eggs of laying hens. Asian-Aust J Anim Sci 12:1661-1666

36. Sugihara S, Kondo M, Chihara Y, Yuji M, Hattori H, Yoshida M (2004) Preparation of selenium-enriched sprouts and identification of their selenium species by high-performance liquid chromatography-inductively coupled plasma mass spectrometry. Biosci Biotechnol Biochem 68(1):193-199

37. Yoshida M, Okada T, Namikawa Y, Matsuzaki Y, Nishiyama T, Fukunaga K (2007) Evaluation of nutritional availability and antitumor activity of selenium contained in selenium-enriched Kaiware radish sprouts. Biosci Biotechnol Biochem 71(9):2198-2205

38. Kim YS, Milner J (2001) Molecular targets for selenium in cancer prevention. Nutr Cancer 40(1):50-54

39. Ghosh S, Karin M (2002) Missing pieces in the NF-kB puzzle. Cell 109(2):81-96

40. Calixto JB, Otuki MF, Santos ARS (2003) Anti-inflammatory compounds of plant origin. Part I. Action on arachidonic acid pathway, 
nitric oxide and nuclear factor $\mathrm{k}$ B (NF-kB). Planta Med 69(11): 973-983

41. Siomek A (2012) NF-kB signaling pathway and free radical impact. Acta Biochim Pol 59(3):323-331
42. Kretz-Remy C, Mehlen P, Mirault ME, Arrigo AP (1996) Inhibition of I kappa B-alpha phosphorylation and degradation and subsequent NF-kappa B activation by glutathione peroxidase overexpression. J Cell Biol 133(5):1083-1093 